\title{
Communications
}

\section{Evaluation of Circular Pin Fed Linearly Polarized Patch Antenna Using Different Substrates}

\author{
Mukkamalla Maruthi Prasada Reddy \\ Department of Electronics \& Communication Engineering, Nova College of Engineering \& Technology, Hyderabad, India \\ Email address: \\ maruthippprasadareddy@gmail.com

\section{To cite this article:} \\ Mukkamalla Maruthi Prasada Reddy. Evaluation of Circular Pin Fed Linearly Polarized Patch Antenna Using Different Substrates. \\ Communications. Vol. 6, No. 2, 2018, pp. 30-33. doi: 10.11648/j.com.20180602.11
}

Received: January 29, 2018; Accepted: February 16, 2018; Published: March 16, 2018

\begin{abstract}
In this paper, a circular pin fed linearly polarized patch antenna is designed, which can be used in radio \& Television, Wimax, GSM, Bluetooth, and WLAN communication systems. The main focus of this paper is to optimize the performance of micro strip patch antenna. In recent times, Wimax based communication applications are widely using circular pin fed linearly polarized patch antenna and it is very familiarized. The proposed antenna design uses 0.5 GHZ frequency band and it is working at narrowband within this band. RT/DUROID 606 material is used for creating the substrate of the micro strip antenna. This new design of the micro strip patch antenna gives high performance in terms of gain and gain bandwidth product.
\end{abstract}

Keywords: Patch Antenna, RT/Duroid, Narrow Band, Pin Fed

\section{Introduction}

At micro wave frequencies physically small sized antenna is well enough to generate desired directivity. Latest communication systems are very small in size, hence antenna size should be very small and can be easily mounted on the system. One such design is micro strip patch antenna, they are highly reliable and robust in nature. Recently, the need for the design of a micro strip patch antenna has increased due to its properties such as, high performance, high gain, low cost. In addition to these properties, it provides an easy user interface and is simple to understand. The topology used for making micro strip patch antenna is pin fed linearly polarized antenna, which is single narrowband patch antenna. The E-shaped micro strip patch antenna is used for WLAN applications. While, Dual wideband Stacked patch antenna is used for both WLAN and WIMAX applications. Due to these properties, the micro strip patch antenna has become very popular in many applications such as in Wimax communication system and mobile applications. The micro strip antenna is bonded to an insulated dielectric substrate. Rectangular patch is most commonly used by the micro strip antenna. The material, which is used for the patch is copper.

The proposed antenna is designed by using substrate material RT/DUROID 606 /Arlan 25N/ Nelco N900 BRF with permittivity 3 and dielectric tangent loss $=0.0004$. The micro strip antenna has a narrowband property, which is a disadvantage of Micro strip patch antenna and shows electromagnetic nature, in some cases. There may be many shapes possible for making micro strip patch antenna such as, rectangular, circular, elliptical, square etc. In this paper, we are designing a circular shaped patch antenna. The circular pin fed linearly polarized micro strip patch antenna is working at a frequency band of 2.5 to $3 \mathrm{GHz}$. The height of the substrate is calculated as $635 \mu \mathrm{m}$ and $1.524 \mathrm{~mm}$, which returns maximum return loss greater than $-42 \mathrm{~dB}$ that improves the gain of the antenna and results high performance. The far-field pattern of micro strip patch antenna also has very good characteristics.

\section{Circular Pin Fed Linearly Polarized Antenna}

Circular pin fed linearly polarized antenna was designed for Wimax communication system with different substrate materials. The conclusion comes out that the antenna gives a maximum gain $5.704 \mathrm{dBi}$ and bandwidth of $1.55 \%$ with height of $1.524 \mathrm{~mm}$. The structural design of the circular pin fed linearly polarized antenna is shown in the figure 1.design 
frequencies are $f_{0}=2.74 \mathrm{GHz}, f_{\min }=2.5 \mathrm{GHz}, f_{\max }=$ $3 \mathrm{GHz}$ and operating frequency is $f=2.85 \mathrm{GHz}$.

In this paper, the aim is to increase the gain of an antenna for using in Wimax communication application system. The proposed patch antenna has maximum gain is about 5.704
dBi when Nelco N900 BRF is used as substrate.The same gain can be achieved with Arlan 25N. But with N900 BRF better gain bandwidth produt can be achieved than Arlan $25 \mathrm{~N}$, as shown in the table 4 .

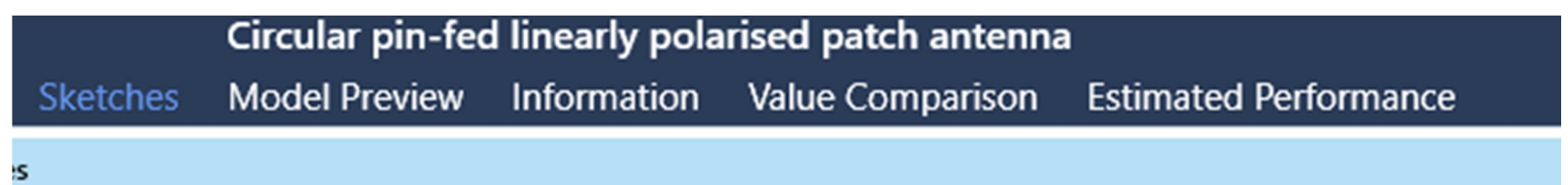

is
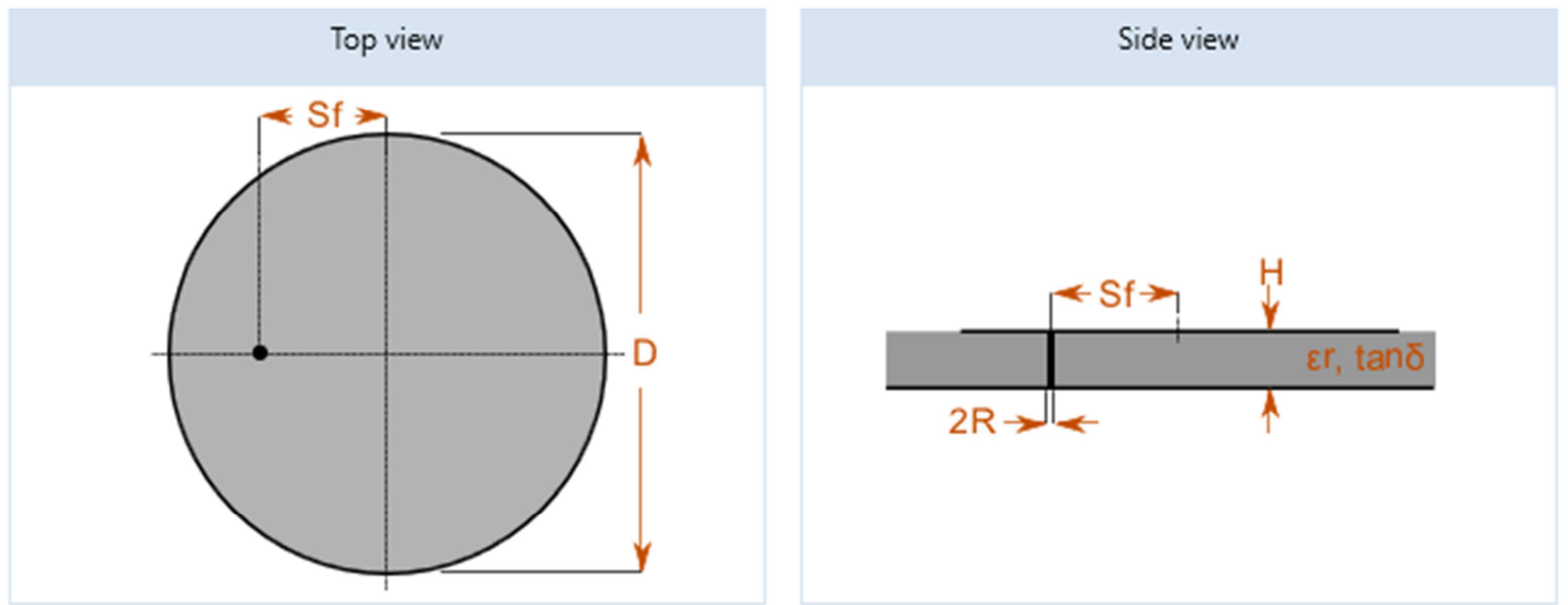

Figure 1. The circular pin fed linearly polarized patch antenna.

\section{Parameter Specification and Values Used in the Desingn of Antenna}

Table 1. Height of Different substrates.

\begin{tabular}{llll}
\hline & $\boldsymbol{\varepsilon}_{\boldsymbol{r}}$ & $\boldsymbol{t a n} \boldsymbol{\delta}$ & $\boldsymbol{H}$ \\
\hline Arlan 25N & 3.58 & $2.5 e^{-3}$ & $1.524 \mathrm{~mm}$ \\
Duroid RT 606 & 6.15 & $2.7 e^{-3}$ & $635 \mu \mathrm{m}$ \\
Nelco N900 BRF & 3 & $4 e^{-3}$ & $1.524 \mathrm{~mm}$ \\
\hline
\end{tabular}

In this paper, our aim is to increase the performance of an antenna. In table 2, we will compare features of different substrates.Design characteristics for different substrates are shown in table 3

Table 2. Diameter and radius of Different substrates.

\begin{tabular}{|c|c|c|c|}
\hline & $D(\boldsymbol{m m})$ & $S F$ & $\boldsymbol{R}$ \\
\hline Arlan $25 \mathrm{~N}$ & 35.69 & 6.078 & $190.5 \mu m$ \\
\hline Duroid RT 606 & 25.79 & 3.926 & $79.38 \mu \mathrm{m}$ \\
\hline Nelco N900 BRF & 35.69 & 6.078 & $190.5 \mu \mathrm{m}$ \\
\hline \multicolumn{4}{|c|}{ Table 3. Specifications of Antenna. } \\
\hline & $x$ dimension & y dimension & z dimension \\
\hline Arlan $25 \mathrm{~N}$ & $35.69 \mathrm{~mm}$ & $35.69 \mathrm{~mm}$ & $1.524 \mathrm{~mm}$ \\
\hline Duroid RT 606 & $25.79 \mathrm{~mm}$ & $25.79 \mathrm{~mm}$ & $635 \mu m$ \\
\hline Nelco N900 BRF & $35.69 \mathrm{~mm}$ & $35.69 \mathrm{~mm}$ & $1.524 \mathrm{~mm}$ \\
\hline
\end{tabular}

Table 4. Result analysis.

\begin{tabular}{llll}
\hline & Gain & Band width & Gain band width product \\
\hline Arlan 25N & $5.704 \mathrm{dBi}$ & $1.460 \%$ & $8.327 \mathrm{dBi}$ \\
Duroid RT 606 & $3.702 \mathrm{dBi}$ & $536.4 \mathrm{e}-3$ & $0.00198 \mathrm{dBi}$ \\
Nelco N900 BRF & $5.704 \mathrm{dBi}$ & $1.55 \%$ & $8.8412 \mathrm{dBi}$ \\
\hline
\end{tabular}

The performance of the antenna designed for Wimax applications depends on certain parameters such as gain, radiation pattern, and gain band width product. These parameters are determined by the simulation method, design techniques and substrates of the micro strip patch antenna. The gain is one of the most important property of the micro strip patch antenna. In the proposed antenna, the received gain is about $5.704 \mathrm{dBi}$ with Arlan $25 \mathrm{~N}$ and Nelco N900 BRF, which is far better than the simple micro strip patch antenna.. Therefore the patch antenna with Nelco N900 BRF substrate gives us better results and performance for use in the Wimax applications.

\section{Conclusion}

The micro strip patch antenna is most widely used antenna design in the Wimax communication system. In this paper, the performance of the antenna is increased by using different substrate materials such as Arlan 25N, RT/ Duroid 606 andNelco N900 BRF. The proposed antenna with Nelco N900 BRF substrate gives a better gain of $5.704 \mathrm{dBi}$ with a maximum gain band width product $8.8412 \mathrm{dBi}$, which greatly 
helps to enhance the performance of the antenna. So that it can be efficiently used in the WiMAX communication

system and other applications.

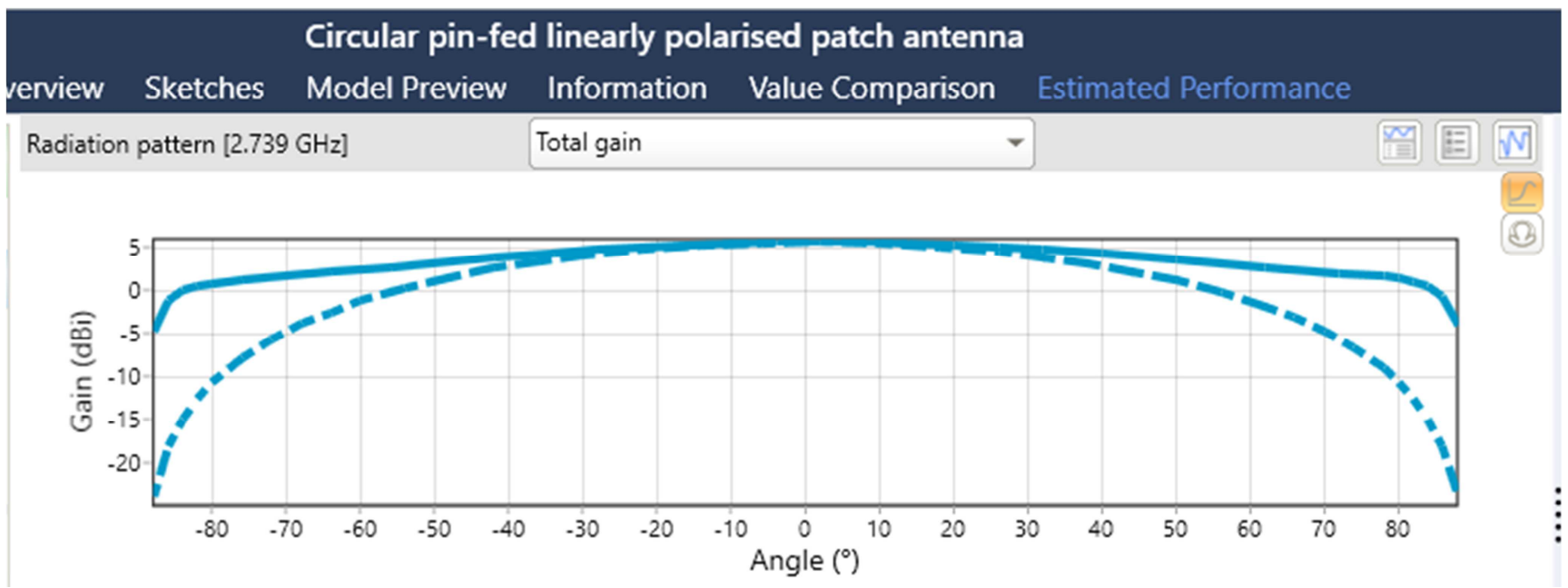

Figure 2. Gain of cicular pin fed antenna.
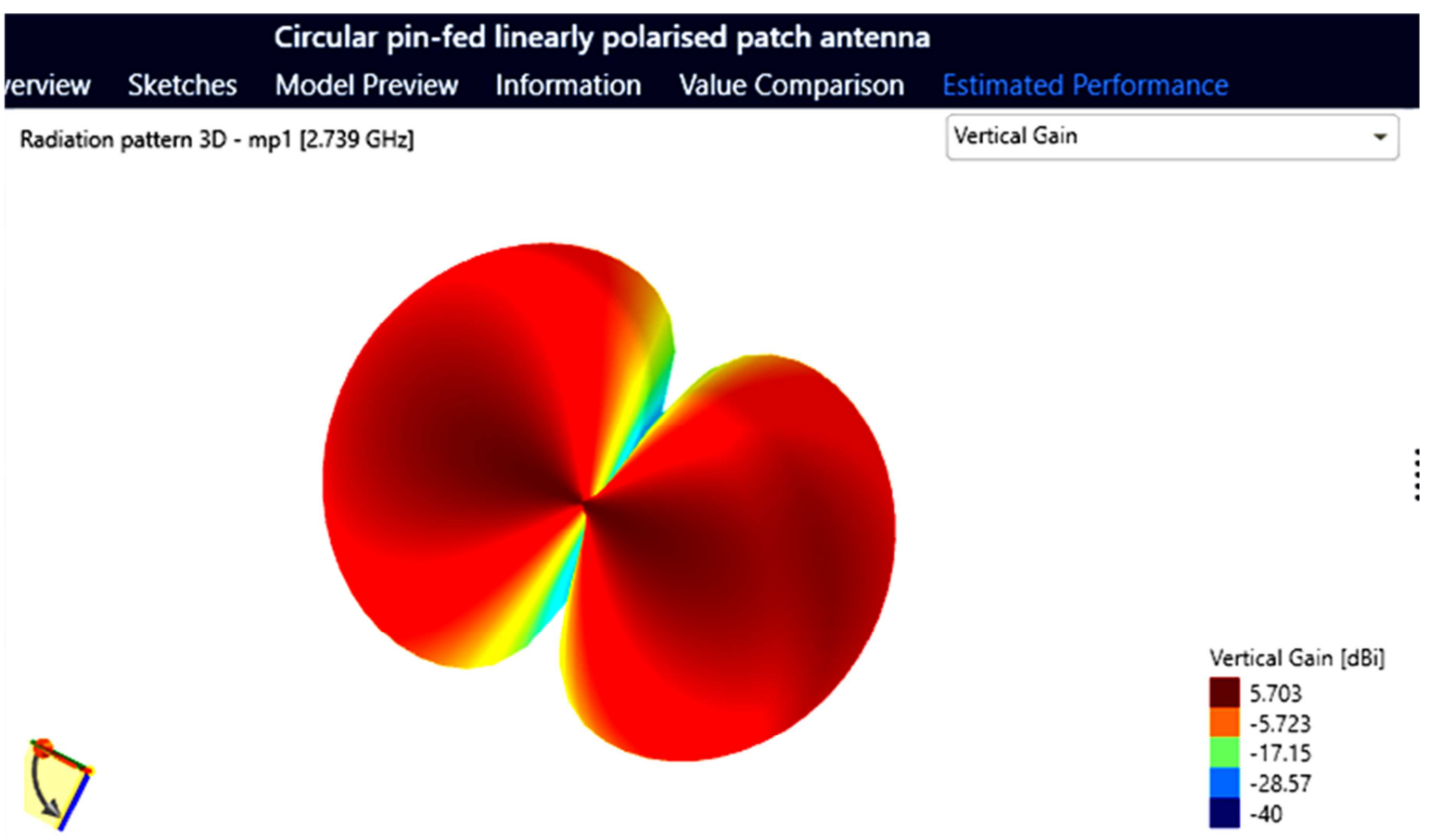

Figure 3. Radiation pattern of circular pin fed linearly polarized patch antenna.

1. Same gain can be achieved with both the substrates Arlan $25 \mathrm{~N}$ and Nelco N900 BRF

2. N900 BRF has better bandwidth over Arlan $25 \mathrm{~N}$

3. N900 BRF has better gain bandwidth product over Arlan $25 \mathrm{~N}$

\section{References}

[1] Amit Kumar gupta, R. K. Prasad and Dr D K srivastava,"design and analysis of quad band rectangular micro strip patch antenna", IOSRJECE, ISSN: 22782834 , Volume 1, Issue 6, p. p 19-23, July-Aug 2012.

[2] S. K. Padhi, N. C. Karmakar, Sr. C. L. Law, and S. Aditya, Sr
IEEE "Transaction on Antennas and Propagation" VOL. 51, NO. 12, DECEMBER 2003.

[3] Puran Gour1 and Ravi Shankar Mishra2 "Bandwidth Enhancement of a Backfire Microstrip Patch Antenna for Pervasive Communication, May 2014”.

[4] M. R. Ahsan, 1 M. T. Islam, 1 M. Habib Ullah, 1, 2 W. N. L. Mahadi, 2 and T. A. Latef "Compact Double-P Slotted InsetFed Microstrip Patch Antenna on High Dielectric Substrate", Microwave and Optical Technology Letters Volume 56, Issue 7, pages 1540-1543, July 2014.

[5] M. T. Islam and M. Samsuzzaman "Miniaturized Dual Band Multislotted Patch Antenna on Polyetrafluroethy lene Glass Microfiber Reinforced for C/X Band Applications" jan 2014. 
[6] C. L. Mak, K. M. Luk, Senior Member, IEEE, K. F. Lee, Fellow, IEEE, and Y. L. Chow "Experimental Study of a Microstrip Patch Antenna with an L-Shaped Probe", 18 march 2014.
[7] Ms. Monika Nandal1, Er. Sagar2 and Dr. Rajesh Goel "A New Approach to Optimal Design of T-shaped TriBand Fractal Microstrip Patch Antenna for Wireless System Applications", Volume 3, Issue 6, June 2014. 